\title{
Solidariedade assimétrica: capital social, hierarquia e êxito em um empreendimento de "economia solidária"
}

\author{
Marcelo Kunrath Silva \\ Universidade Federal do Rio Grande do Sul (UFRGS)
}

\author{
Gerson de Lima Oliveira \\ Universidade Federal do Rio Grande do Sul (UFRGS)
}

\begin{abstract}
Solidariedade assimétrica: capital social, hierarquia e êxito em um empreendimento de "economia solidária"

Resumo: O objetivo deste artigo ${ }^{1}$ é analisar como se estruturam as relações internas em uma cooperativa autogerida, a fim de identificar os fatores que possibilitam - ou bloqueiam - a instituição do modelo igualitário, proposto pela economia solidária. Partindo da hipótese de que a desigualdade em termos da distribuição de capital social tende a ser um importante fator explicativo da hierarquia nas posições ocupadas pelos participantes de empreendimentos econômicos populares, utiliza-se a análise de redes sociais como recurso metodológico para apreender as relações entre os membros da cooperativa pesquisada. As significativas assimetrias observadas nestas relações são explicadas, em grande medida, pela marcante concentração de capital social por uma das trabalhadoras, que, praticamente, monopoliza as relações da cooperativa com agentes externos em posições institucionais privilegiadas. O alto estoque de capital social concentrado por esta trabalhadora limita a possibilidade de instituição de relações igualitárias entre os membros da cooperativa pesquisada, ao mesmo tempo em que, paradoxalmente, constitui-se em um importante fator para o êxito econômico do empreendimento, ao possibilitar o acesso a recursos e a oportunidades fundamentais para tal êxito.
\end{abstract}

Palavras-chave: economia solidária, capital social, cooperativismo, redes sociais.

Asymmetric Solidarity: Social Capital, Hierarchy and Success in a "Solidarity Economics" Enterprise Abstract: The purpose of this article is to analyze how the internal relations in a self-generating cooperative are structured, in order to identify the factors that permit - or block - the institution of an egalitarian model, as proposed by solidarity economics. Based on the hypothesis that inequality in terms of the distribution of social capital tends to be an important factor in establishing the hierarchy of positions occupied by participants of popular economic enterprises, it uses the analysis of social networks as a methodology to learn about the relations between the members of the cooperative studied. The significant asymmetries observed in these relationships are explained, to a large degree, by the strong concentration of social capital held by one of the women workers, who practically monopolizes the relations of the cooperative with outside agents in important institutional positions. The high stock of social capital concentrated by this worker limits the ability of the institution to have egalitarian relations among the cooperative members, while paradoxically, it constitutes an important factor for the economic success of the operation, by allowing access to resources and opportunities essential to this success.

Key words: solidarity economics, social capital, cooperative movement, social networks. 


\section{Introdução}

Em meados da década de 1990, entra em cena uma nova concepção de cooperativismo denominada "economia solidária", visando oferecer uma alternativa aos trabalhadores afetados negativamente pelas transformações ocorridas no mundo do trabalho nas décadas de 1970 e 1980 . Nesse período, ocorre a crise do antigo modelo fordista-taylorista de produção (HARVEY, 1996), paralelamente à emergência de inovações tecnológicas e novas formas de gestão da produção que reduzem a necessidade de mão-de-obra e/ou possibilitam a transferência das unidades produtivas para locais que ofereçam custos de produção mais baixos. Como resultado, observa-se o crescimento do desemprego em praticamente todo o mundo, especialmente em países centrais como Estados Unidos e Inglaterra. Essa situação é agravada pelas duas crises do petróleo da década de 1970, pelas dificuldades de financiamento do Estado de BemEstar Social na Europa ocidental e pela adoção de políticas econômicas neoliberais (primeiramente por Pinochet no Chile, depois por Thatcher na Inglaterra e Reagan nos EUA) (HOBSBAWM, 1995).

Tamanhas transformações fizeram da década de 1980 um período de recessão e crises econômicas (no Brasil denominada de "a década perdida"), que logicamente se refletiram na esfera social. Os efeitos mais imediatos, além do crescente desemprego mencionado, foram o aumento das desigualdades sociais e da concentração de renda, o aumento da pobreza e o enfraquecimento dos sindicatos e demais instituições representativas dos trabalhadores (PINTO, 2006).

É neste contexto que a proposta de economia solidária ganha espaço, primeiramente na França e, posteriormente, como experiência concreta na América Latina e no restante da Europa. Mais do que oferecer uma alternativa de trabalho e renda, a economia solidária tem como objetivo a construção de um modelo econômico baseado na relação entre iguais, através da eliminação das desigualdades e da exploração do trabalho fundadas em relações de propriedade. Assim, uma cooperativa que funciona sob os preceitos da economia solidária deve primar pelas relações simétricas entre os seus associados, através da implantação de um processo de autogestão que garanta a todos o direito de partici- par de forma igualitária da gestão e dos resultados do empreendimento econômico.

Com o considerável crescimento das experiências de economia solidária na década 1990 e na primeira década do século 21 - cooperativas de produção, feiras de comercialização, clubes comunitários de troca, bancos fornecedores de crédito solidário, entre outras -, também crescem os estudos acadêmicos sobre estas experiências (SINGER, 2002; FRANÇA FILHO; LAVILLE, 2004; GAIGER, 2004; CATTANI, 2004).

Inserindo-se neste campo de estudos, o objetivo geral deste artigo é analisar como se estruturam as relações internas em uma cooperativa autogerida, a fim de identificar os fatores que possibilitam - ou bloqueiam - a instituição do modelo igualitário proposto pela economia solidária. Mais especificamente, parte-se da hipótese de que, em um contexto no qual atuam agentes relativamente semelhantes no que se refere aos atributos socioeconômicos, a desigualdade em termos da distribuição de capital social tende a ser um importante fator explicativo das eventuais assimetrias nas posições ocupadas pelos indivíduos atuantes neste espaço social. Tais assimetrias, por sua vez, limitariam a possibilidade de instituição de relações igualitárias entre os membros do empreendimento solidário pesquisado, ao mesmo tempo em que, paradoxalmente, constituem-se em um importante fator para o êxito econômico do empreendimento.

A análise desenvolvida neste artigo busca, assim, enfocar um aspecto pouco analisado pela literatura sobre economia solidária, em grande medida concentrada no debate sobre o significado macroestrutural deste modelo como alternativa e/ou complemento à economia capitalista (GAIGER, 1999, 2006). Nesse sentido, seguindo a vertente aberta por algumas pesquisas recentes (AZAMBUJA, 2004, 2007; ROSENFIELD, 2003), aborda-se a microdinâmica interna dos empreendimentos solidários, problematizando a aparente homogeneidade de seus atores e relações constitutivos. Tal perspectiva, ao evitar o enfoque normativo que caracteriza grande parte da literatura, permite identificar e analisar objetivamente fatores e processos que viabilizam ou bloqueiam a constituição dos empreendimentos solidários como espaços de construção de novos sujeitos sociais fundados em relações igualitárias.

Para o desenvolvimento da análise, então, este artigo encontra-se estruturado em seções que apre- 
sentam, na ordem: o referencial teórico, enfocando particularmente o conceito de capital social; os procedimentos metodológicos da pesquisa; a cooperativa pesquisada; a estrutura de relações e posições dos membros da cooperativa, analisando os efeitos da desigualdade na distribuição de capital social como fator explicativo das assimetrias observadas; por fim, a conclusão sintetizando os resultados da pesquisa e apontando alguns tópicos para futuras investigações.

\section{Capital social: relações e recursos relacionais}

O conceito de capital social tem apresentado, na última década, uma vertiginosa disseminação, tendo centralidade não apenas no vocabulário teórico das ciências sociais, mas sendo também grandemente apropriado por agências de desenvolvimento, instituições governamentais e organizações não-governamentais. No entanto, como diversos conceitos das ciências sociais, o conceito de capital social é marcado por uma polissemia, podendo apresentar diversos conteúdos a depender da perspectiva utilizada (PORTES, 2000b; LIN, 2001). Neste artigo, o conceito de capital social utilizado é aquele que segue a perspectiva teórica de Pierre Bourdieu, para quem o capital social é

[...] o conjunto de recursos atuais ou potenciais que estão ligados à posse de uma rede durável de relações mais ou menos institucionalizadas de interconhecimento e de inter-reconhecimento ou, em outros termos, à vinculação a um grupo, como conjunto de agentes que não somente são dotados de propriedades comuns (passíveis de serem percebidas pelo observador, pelos outros ou por eles mesmos), mas também são unidos por ligações permanentes e úteis (BOURDIEU, 1998, p. 67).

De acordo com esta definição, o conceito de capital social busca apreender um recurso de caráter relacional, ou seja, um recurso cuja produção e utilização implicam a inserção dos agentes em uma rede de relações sociais. Neste sentido, o capital social pode ser entendido como os recursos materiais e/ou simbólicos (informações, influência, prestígio, confiança, reconhecimento, suporte) que indivíduos e grupos adquirem através das relações que constroem, acumulam e mantêm. Em outras palavras, a possibilidade de acessar recursos (e os próprios recursos possíveis de serem acessados) através de contatos, os quais estabelecem a posição estrutural dos atores sociais em relação a outros, é o que define o capital social, segundo a perspectiva de Bourdieu.

Em sua sistematização sobre o conceito de capital social, Portes (2000a) ressalta que, na teoria de Bourdieu, o capital social pode ser convertido em outras formas de capital, tal como capital econômico, simbólico ou cultural. Esta possibilidade depende, no entanto, da configuração da rede de relações em que indivíduos e grupos estão imersos e, particularmente, da posição que estes ocupam na mesma.

Tal afirmação é importante de ser destacada, uma vez que desfaz certa confusão entre os conceitos de relações sociais e de capital social: se, por um lado, o capital social sempre se funda em relações sociais, por outro, nem todas as relações sociais têm a mesma "produtividade" em termos da geração de capital social para os agentes nelas envolvidos. Como colocado acima, esta "produtividade" vai ser definida pela configuração das relações em foco (que estabelece os recursos disponíveis) e pela hierarquia de posições na rede relacional (que determina as diferentes possibilidades dos agentes se apropriarem dos recursos produzidos e/ou em circulação nesta rede).

Esta diferenciação conceitual entre relações sociais e capital social introduz a necessidade de analisar se, como e por que determinadas relações sociais se tornam geradoras de capital social enquanto outras não apresentam esse potencial. Tais questionamentos sobre o valor diferencial das relações em termos de sua capacidade de gerar "ganhos" para os indivíduos encontra-se no cerne da clássica distinção estabelecida por Granovetter (1973; 1983) entre laços fracos e laços fortes. Para este autor, haveria uma tendência dos indivíduos estabelecerem laços marcados por forte investimento emocional e intenso contato (laços fortes) com outros indivíduos em posição social relativamente assemelhada (tendência à homofilia) e que apresentem vínculos entre si (tendência à transitividade). Tal similaridade de posição e de vínculos compartilhados, no entanto, faz com que os laços fortes sejam pouco eficazes no sentido de possibilitar aos indivíduos acessarem recursos que circulam nas redes de indivíduos em posições sociais distintas. Neste sentido, segundo o autor, os laços fracos - ou seja, aqueles laços de menor intensidade que funcionam como "pontes" conectando atores posicionados em distintos espaços sociais - tenderiam a ser muito mais valiosos em termos de viabilizar o acesso a recursos que não estão disponíveis na rede formada pelos indivíduos ligados por laços fortes. Este aspecto seria particularmente importante para indivíduos oriundos dos segmentos subalternos da sociedade, cuja rede de vínculos fortes tenderia a estar constituída por indivíduos que compartilham a mesma posição de subalternidade.

Desenvolvendo o argumento de Granovetter, autores buscaram diferenciar tipos de relações a partir de suas características distintas e, também, por suas potencialidades diferenciadas em termos da geração de capital social. Para a análise desenvolvida neste artigo, utiliza-se a categorização elaborada por 
Marteleto e Silva (2005), que estabelecem uma diferenciação entre ${ }^{2}$ :

a) Relações sociais de ligação - são os laços constituídos geralmente entre indivíduos assemelhados por características socioeconômicas comuns e convivência intensa (os laços fortes de Granovetter), sendo a base para a geração de identidades compartilhadas, confiança e comprometimento;

b) Relações sociais de ponte - são os laços constituídos entre distintas redes de indivíduos que ocupam posições relativamente próximas no espaço social, os quais possibilitam a ampliação das fontes de informações e conhecimentos, além de suporte para o desenvolvimento de iniciativas conjuntas;

c) Relações sociais de conexão - são aqueles laços estabelecidos entre indivíduos e redes em distintas posições no espaço social (os laços fracos de Granovetter), os quais possibilitam o acesso a recursos distintos daqueles disponibilizados pelas relações entre "iguais".

A partir dessas categorias, torna-se possível, então, problematizar as relações estabelecidas no interior do empreendimento solidário pesquisado, buscando identificar as diferenças em termos da configuração das redes pessoais de seus componentes e, especialmente, como estas diferenças são geradoras de desigualdades em termos da distribuição de capital social e, por decorrência, das posições dos agentes neste espaço social. Na medida em que são agentes que compartilham atributos socioeconômicos relativamente semelhantes, é esta diferença em termos das redes pessoais (seu volume - número de laços - e, especialmente, composição - tipo de laços) que permite compreender a expressiva desigualdade de posições observada no trabalho de campo.

\section{Metodologia da pesquisa}

Na medida em que o capital social é um recurso fundamentalmente relacional, a metodologia de Análise de Redes Sociais (ARS) apresentou-se como instrumento privilegiado para operacionalização da análise. Contrapondo-se a uma abordagem substancialista da realidade social, a ARS oferece recursos metodológicos para apreender a configuração das relações estabelecidas entre os agentes no espaço social, a partir da qual, então, torna-se possível tanto analisar os efeitos desta configuração quanto os mecanismos causais que a determinam.

O caso em análise é particularmente adequado para o uso da ARS, uma vez que a relativa semelhança de atributos (escolaridade, renda, local de moradia e gênero) entre os agentes do empreendimento solidário impossibilita o uso de modelos analí- ticos baseados em explicações atributivas; ou seja, modelos analíticos que partem do pressuposto de diferenças de atributos dos casos (no caso, dos agentes) permitem explicar diferenças nos resultados (no caso, posições ocupadas no interior do empreendimento solidário). Na medida em que os atributos dos agentes tendem a se assemelhar, torna-se necessário buscar outra perspectiva analítica para explicar os resultados observados no trabalho de campo: neste caso, diferenças de inserção relacional dos atores e a consequente desigualdade nos estoques de capital social dos mesmos. Neste sentido, como destacam Marteleto e Silva (2005, p. 46),

\begin{abstract}
A posição de cada indivíduo na rede depende do capital social e informacional que consiga agregar para si próprio e para o conjunto. A margem de decisão de um indivíduo inserido em uma rede social está sujeita à distribuição de poder, à estrutura de interdependência e de tensões no interior do grupo. É a ocupação de determinadas posições na rede da comunidade, de especial acesso a informações, que determina o sucesso das ações dos indivíduos e seus grupos.
\end{abstract}

Asssim, utilizou-se a metodologia de Análise de Redes Sociais (ARS) como instrumento para apreensão das relações sociais instituídas no seio da cooperativa. Através desta metodologia buscou-se identificar: 1) como se dá a construção de diferentes posições e papéis no interior da rede de relações formada no âmbito da cooperativa analisada, através da identificação dos agentes que desempenham funções de maior centralidade e importância; 2) que atributos permitem tal diferenciação e; 3) como estas diferenças se relacionam com o objetivo de implantação de um modelo de relações igualitárias no interior do empreendimento solidário.

A partir desta perspectiva, foram realizadas observações e entrevistas ${ }^{3}$ buscando identificar as diferenças na configuração das redes pessoais dos vários indivíduos que atuam na cooperativa, ao mesmo tempo em que se buscava apreender a estrutura de posições e de relações entre esses agentes. Mais especificamente, buscou-se identificar o acesso diferenciado aos distintos tipos de relações (de ligação, de ponte e de conexão) e como esta diferença possibilitava explicar as distintas posições ocupadas pelos agentes no âmbito da cooperativa.

\section{A Cooperativa Univens}

Esta pesquisa tem como objeto empírico a Cooperativa Univens ${ }^{4}$ (abreviatura de Unidas Venceremos), localizada na zona norte do município de Porto Alegre. A cooperativa foi fundada em 1996, por um 
grupo de 35 mulheres que buscavam uma alternativa de emprego que solucionasse o problema da dupla jornada feminina: a dificuldade de conciliar trabalho doméstico com trabalho assalariado. Hoje, a cooperativa possui 25 membros, dos quais 23 são mulheres e dois são homens. Desses 25 membros, apenas cinco compuseram o grupo inicial que fundou a cooperativa. Ao longo do tempo, a Univens se consolidou enquanto uma alternativa de trabalho e renda para suas integrantes e hoje é considerada uma cooperativa modelo não apenas em termos de êxito econômico, mas, especialmente, em termos da efetivação dos princípios da economia solidária.

A cooperativa iniciou suas atividades prestando serviços de costura e confecção de uniformes para escolas e outras entidades da região. Atualmente, a Univens fabrica diversos tipos de produtos têxteis tais como bandeiras, bolsas, bonés e camisetas para sindicatos, escolas, movimentos sociais, associações, clubes e afins. Fornece, também, material para eventos como congressos, seminários e outras espécies de encontros políticos, científicos e culturais.

O processo produtivo da cooperativa é dividido em três setores: a costura, o corte e a serigrafia, no qual trabalham os dois homens. No primeiro, a remuneração é proporcional ao número de peças produzidas. Nos outros dois setores, a remuneração é definida por horas de trabalho cumpridas. O horário de trabalho é flexível, conferindo certa autonomia às trabalhadoras para definirem sua jornada, desde que se cumpram as metas de produção.

As decisões sobre a gestão da cooperativa são tomadas de maneira coletiva, através de assembleias mensais. Junto com o estatuto, a assembleia é a instituição mais importante da cooperativa, sendo as decisões tomadas através de votação de todos os membros. Os cargos administrativos - tais como presidência, tesouraria e conselho fiscal - são preenchidos através de processo eleitoral, realizado a cada três anos. A rotatividade das posições administrativas é estimulada pela determinação estatutária de que a ocupação de tais cargos é uma atividade extra a ser desempenhada pela trabalhadora; ou seja, todas as ocupantes desses cargos mantêm o compromisso com a realização das atividades produtivas, uma vez que o desempenho de cargos administrativos não acarreta em diminuição do trabalho na produção.

Todas as trabalhadoras e os dois trabalhadores são moradores da região na qual a cooperativa está localizada e, em geral, possuem trajetórias similares. A grande maioria provém de famílias pobres e começaram a trabalhar ainda na juventude. A maioria já possuía experiência de trabalho na indústria têxtil previamente ao ingresso na cooperativa.

A situação atual da Univens é estável. A cooperativa consolidou-se no mercado e hoje pode oferecer aos seus membros uma renda mensal acima da média salarial da categoria no setor privado. Um dos principais fatores para este relativo sucesso da Univens pode ser atribuído à rede de relações interorganizacionais na qual a cooperativa encontrase inserida. $\mathrm{O}$ suporte inicial à Univens foi, em grande medida, dado por entidades sociais e instituições municipais. De 1999 a 2004, a cooperativa esteve sediada no espaço cedido pela Incubadora Popular de Cooperativas e Grupos da Prefeitura de Porto Alegre. $\mathrm{O}$ apoio de uma ONG espanhola possibilitou, posteriormente, a construção de uma sede própria, na qual a Univens opera atualmente. Em entrevistas com as associadas, foi possível constatar o quanto esta articulação da cooperativa com entidades e instituições governamentais e não-governamentais foi importante para que o empreendimento pudesse se consolidar. Os vínculos com outras cooperativas, sindicatos e partidos políticos (particularmente o Partido dos Trabalhadores) também é um fator importante na consolidação de um mercado consumidor para os produtos da cooperativa ${ }^{5}$. Além desses vínculos, a Univens conta ainda com o apoio de universidades e entidades de apoio a cooperativas que oferecem cursos de capacitação profissional às trabalhadoras do empreendimento. De acordo com uma trabalhadora entrevistada:

\begin{abstract}
A P. (presidente) foi buscar ajuda fora. O sindicato dos metalúrgicos ajudou no começo, o PT também. A P. é do PT. [...] Além da incubadora da SMIC, o SEBRAE ajuda com os cursos. A Unisol ajuda nos dando crédito e com cursos também. [...] A prefeitura não ajuda mais como antes. A gente cresce mais com a ajuda das ONGs de fora, principalmente da Espanha que ajudou na construção do prédio. Seguido vem um pessoal da Espanha e da França pra ver como andam as coisas e nos ajudar. Agora o Banco do Brasil vai ajudar na ampliação do prédio também. Isolado não dá certo, a ideia é sempre estar ligado com outros grupos (L.G., 58 anos, costureira) $)^{6}$.
\end{abstract}

Conforme destacado neste depoimento, a presidente da Univens é a principal (e, de fato, praticamente a única) responsável pela construção destas relações externas da cooperativa. Tal centralidade, conforme análise da próxima seção, é um dos elementos-chave na definição das assimetrias de posições e papéis das trabalhadoras no interior na cooperativa.

\section{Capital social e assimetria nas relações entre os membros da Cooperativa Univens}

Conforme salientado na seção anterior, a cooperativa pesquisada incorporou na sua estrutura formal um conjunto de regras e procedimentos que visa garantir a instituição de um espaço social fundado em 
relações igualitárias entre todos os seus membros: assembleias gerais, eleições para ocupação dos cargos administrativos, obrigação de todos participarem do processo produtivo, entre outros elementos. Em função da presença desses mecanismos, somada à relativa homogeneidade socioeconômica dos membros da cooperativa, a expectativa seria encontrar um alto grau de simetria no interior deste empreendimento, aproximando-o do ideal igualitário que marca a proposta da economia solidária.

No entanto, a partir das observações e entrevistas realizadas, percebe-se, ao contrário, uma expressiva assimetria nas relações no interior da cooperativa. Apesar da igualdade formal de todos os membros, as próprias trabalhadoras identificam a existência de um pequeno grupo - e, dentro deste, de um indivíduo em particular - que ocupa uma posição diferenciada nesse espaço social, conferindo aos seus membros uma relativa superioridade sobre os demais. Mesmo que tal superioridade não se traduza em distinções formais entre as trabalhadoras, sendo ressaltado de forma unânime que todas estão submetidas às regras igualitárias que orientam o empreendimento, observa-se claramente que alguns indivíduos possuem maior autoridade e prestígio no interior da cooperativa.

De acordo com os depoimentos colhidos, pode-se identificar a existência de um subgrupo no interior da rede da cooperativa, formado pelas cinco remanescentes do grupo inicial que criou a Univens. Marcado por um alto grau de identificação interpessoal e com a proposta da economia solidária, esse grupo apresenta um claro papel de animador do conjunto dos trabalhadores, buscando gerar um envolvimento que vá além da visão da cooperativa como mera alternativa de trabalho e renda. Usando a tipologia de Azambuja (2007, p. 97), este subgrupo estaria dotado de um "sentido político do trabalho autogerido", segundo o qual "o trabalho autogerido representa a possibilidade da consecução de um projeto político, de inserção num processo de mudança da realidade social e do comportamento das pessoas."

No interior deste subgrupo, identificado e distinguido pelas entrevistadas como as "antigas", observa-se a marcante ascendência de uma trabalhadora. Essa trabalhadora, denominada por uma entrevistada como sendo a "alma" da Univens, ocupa a presidência da cooperativa desde a sua fundação e é identificada por todas as entrevistadas como o membro com maior autoridade e prestígio. Esta centralidade faz com que algumas entrevistadas salientem que a própria sobrevivência da cooperativa é totalmente dependente da presença e atuação da presidente:

A P. é crucial aqui. A gente deixa um pouco pra ela decidir, mas ela cutuca a gente pra se envolver mais.
Ela acaba envolvendo a gente. [...] Começou com a P., a ideia inicial foi dela, ela desde o começo é quem organiza e que puxa, envolve o pessoal. [...] Não sei se sem ela continuaria, acho que não daria certo. [...] Eu me escondo um pouco, mas a chance de se integrar mais e tomar decisões existe. [...] Mas quem faz o meio de campo é a P., é sempre ela. Ela viaja também pra conseguir ajuda pra cooperativa. Esses tempos ela foi pra São Paulo conseguir ajuda pra ampliação do prédio (D., 55 anos, costureira).

A partir da identificação dessa diferenciação entre as trabalhadoras da cooperativa, que implica em significativa assimetria entre as mesmas, a questão que se coloca para a análise é explicar por que e como se produziu tal assimetria, independentemente da relativa homogeneidade socioeconômica entre elas e da expressa intencionalidade de construir um espaço social fundado em relações igualitárias.

Conforme expresso nas seções anteriores parte-se do argumento que esta assimetria se funda na desigual distribuição de capital social (em termos de volume e, especialmente, de tipo) entre os participantes da cooperativa. De acordo com os dados coletados, esse argumento parece encontrar significativa sustentação empírica. Primeiramente, identifica-se que o subgrupo das "antigas" desempenha um papel central em termos da constituição e reprodução das 'relações de ligação' entre as trabalhadoras da cooperativa. Sendo as portadoras da história e dos ideais que orientaram a constituição da Univens, essas trabalhadoras acabam sendo as principais responsáveis pelo processo de identificação coletiva que fundamenta a confiança e a solidariedade no interior do grupo.

No que se refere às "relações de ponte" e às "relações de conexão", ou seja, às relações da cooperativa com outras organizações e instituições, observase um quadro ainda mais concentrado que o observado nas relações de ligação. De fato, como salientado anteriormente, tais relações de ponte e de conexão são praticamente monopolizadas pela presidente da cooperativa, levando a que muitas das entrevistadas apresentem um relativo desconhecimento sobre como tais relações foram estabelecidas e como elas se estruturam. Isto é ilustrado pelo seguinte depoimento de uma entrevistada:

Sei que tem uma ONG da Espanha que ajuda, mas não sei muito bem como se deu isso. Não sei se eu já tinha entrado na Univens quando isso aconteceu. Tem que ver com a P. Ela deve saber, porque essas coisas são mais com ela (J., 26 anos, costureira).

Retomando o argumento de Marteleto e Silva, referido na seção metodológica, esse domínio exercido pela presidente sobre relações e informações que são 
cruciais para a sustentação do empreendimento solidário é um elemento fundamental para a definição da posição de superioridade que este indivíduo ocupa frente aos outros membros da cooperativa.

$\mathrm{Na}$ medida em que as relações externas são eficazes para a obtenção de recursos para a cooperativa (visibilidade pública, acesso a mercados, capacitação, financiamento de projetos etc.), sendo um dos fundamentos de seu sucesso enquanto empreendimento econômico, elas são também um fator central para a geração e manutenção do prestígio e da autoridade da presidente entre as trabalhadoras da Univens, uma vez que esta é a grande responsável por essas relações. Ou seja, o controle sobre essas relações de ponte e de conexão é o fundamento do significativo estoque de capital social da presidente da Univens, sobre o qual se sustenta sua posição de superioridade na estrutura de posições da cooperativa.

A capacidade da presidente de acumular este capital social amplo e diversificado e, assim, assumir esta posição de superioridade em relação às outras trabalhadoras da cooperativa, está diretamente relacionada à sua trajetória de envolvimento político-associativo. Nesta trajetória foram sendo construídas relações com diversos indivíduos e organizações que possibilitaram, posteriormente, o acesso a recursos e oportunidades para a Univens.

Neste sentido, foi sua ligação com o Partido dos Trabalhadores, com o Sindicato dos Metalúrgicos de Porto Alegre e com diversas organizações e movimentos sociais do município que possibilitou a captação de recursos e apoio para a formação da cooperativa. Especialmente após a conquista da Prefeitura Municipal pelo Partido dos Trabalhadores, em 1989, estas relações se "valorizaram", na medida em que indivíduos destas organizações sociais e políticas passaram a ocupar postos no governo e, assim, a acessar e controlar a utilização de recursos da administração municipal. Como foi destacado anteriormente, a instalação da Univens no espaço cedido pela Incubadora Popular de Cooperativas e Grupos da Prefeitura de Porto Alegre, durante o período de cinco anos, foi fundamental para a viabilização do empreendimento nos momentos iniciais.

Esta mesma inserção político-associativa, juntamente com as atividades desenvolvidas pela própria Univens, possibilitou à presidente inserir-se de forma destacada nas redes ligadas à economia solidária que estavam sendo constituídas no mesmo período de formação da cooperativa. Representando uma experiência que se tornou um caso exemplar de êxito, a presidente da Univens passou a acessar e transitar em diversos eventos (seminários, congressos, fóruns) relacionados à economia solidária, constituindo um amplo leque de relações com os diversos atores (cooperativas, ONGs, pesquisadores, gestores públicos) participantes destes eventos. Tais contatos, por sua vez, oportunizaram que a cooperativa pudesse obter recursos importantes para sua consolidação (informações, reconhecimento, capacitação, financiamentos, mercados).

Assim, na medida em que as relações externas da cooperativa se fundam basicamente nas relações de ponte e de conexão construídas pela presidente (tanto no período anterior à constituição da cooperativa, quanto no período posterior) e, particularmente, na medida em que estas relações não são facilmente transferíveis aos outros membros da cooperativa (uma vez que se fundam na trajetória pessoal da presidente, na qual se forjaram determinadas disposições e capacidades que a distinguem das outras trabalhadoras), torna-se compreensível a expressiva assimetria observada no caso em estudo.

\section{Conclusão}

A análise do caso da Cooperativa Univens possibilita problematizar uma série de aspectos das experiências de economia solidária atualmente em curso no Brasil e em outras partes do mundo. Em primeiro lugar, ela identifica tensões entre o objetivo normativo de instituição de relações igualitárias e a dinâmica concreta de relações entre atores desiguais em termos de seus recursos relacionais. Geralmente ocultos por perspectivas centradas nos atributos dos agentes (renda, escolaridade, religião, raça etc.) como fundamento das diferenças de autoridade e prestígio, estes recursos relacionais - que formam o capital social dos agentes - mostram-se fundamentais para explicar assimetrias entre os "iguais", tal como observado na Univens.

Mas, se o caso da Univens identifica obstáculos à instituição de relações igualitárias em empreendi- 
mentos solidários, ele mostra também como mecanismos institucionais (regras e procedimentos) e disposições ideológicas (comprometimento com os princípios da economia solidária) podem operar como barreiras para impedir que a desigualdade, em termos de recursos relacionais, autoridade e prestígio, desdobre-se em desigualdade econômica e institucional. Ou seja, não foi observada a conversão da posição de superioridade das "antigas" na rede da cooperativa em desigualdade de remuneração, de trabalho no processo produtivo ou de subordinação às regras igualitárias. Ao contrário, as exigências associadas à ocupação de posições superiores tendem a impor custos significativos (em parte, é claro, contrabalançados pelas oportunidades de reconhecimento público, viagens, acesso a autoridades etc.) que se somam àqueles compartilhados por todas as trabalhadoras.

Uma segunda conclusão que pode ser extraída do caso estudado, é que a desigualdade observada, ao contrário de ser um elemento de ameaça ao êxito da cooperativa, parece se constituir em um dos principais fatores explicativos de seu sucesso. $\mathrm{O}$ fato de a Univens ser considerada modelo no que diz respeito à organização interna de participação e gestão, de acordo com os preceitos da economia solidária, dá-se dá justamente pela existência de um grupo e, especialmente, de um indivíduo central, fortemente engajado a essa causa. Tal conclusão, aparentemente paradoxal, chama a atenção para um aspecto crescentemente abordado pela denominada Nova Sociologia Econômica: a centralidade de recursos não econômicos para a viabilidade de empreendimentos econômicos.

No caso da Univens, fica claro que o seu sucesso está diretamente vinculado à capacidade da presidente de mobilizar sua rede ampla e diversificada de relações políticas e associativas no sentido de obter recursos essenciais para manutenção da cooperativa. Em um contexto de profunda desigualdade como o brasileiro, estas relações permitem acessar recursos particularmente escassos para os segmentos populares, possibilitando sua inserção em um mercado pouco permeável e concentrador da riqueza.

Assim, ao invés da condenação normativa da desigualdade de recursos relacionais como ameaça à proposta da economia solidária, este artigo conclui com a sugestão de dois importantes tópicos para futuras pesquisas comparativas: a análise dos mecanismos que limitam (ou não) a conversão da desigualdade de capital social em outras formas de desigualdade nos empreendimentos solidários; a análise de como diferenças no estoque de capital social dos membros de empreendimentos solidários (especialmente das relações de ponte e de conexão) afetam o desempenho econômico desses empreendimentos. A compreensão desses processos pode ajudar no enfrentamento das tensões que marcam os empreendimentos solidários, contribuindo, assim, para sua consolidação enquanto espaços alternativos de trabalho, renda e igualdade.

\section{Referências}

AZAMBUJA, L. R. Os valores da economia solidária: um estudo sobre a heterogeneidade ideológica de trabalhadores de cooperativas autogeridas. 2004. $80 \mathrm{f}$. Monografia de conclusão de curso (Graduação em Ciências Sociais) - Departamento de Sociologia, Universidade Federal do Rio Grande do Sul, Porto Alegre 2004.

Os sentidos do trabalho autogerido: um estudo a partir dos trabalhadores de cooperativas de economia solidária. 2007. 145 f. Dissertação (Mestrado em Sociologia) - Programa de Pós-Graduação em Sociologia, Universidade Federal do Rio Grande do Sul, Porto Alegre, 2007.

BOURDIEU, P. Escritos de educação. Petrópolis: Vozes, 1998.

CATTANI, A. (Comp.). La otra economia. Buenos Aires: Ed. Altamira, 2004.

FRANÇA FILHO, G. C. de; LAVILLE, J. Economia solidária: a abordagem internacional. Porto Alegre: Editora daUFRGS, 2004.

GAIGER, L. I. La solidariedad como una alternativa económica para los pobres. Revista de Economía Pública, Socialy Cooperativa. Valencia: CIRIEC, n. 31, p. 187-205, jun. 1999.

. Emprendimientos económicos solidários. In: CATTANI, A., (Comp.). La otrae Economia. Buenos Aires: Ed. Altamira, 2004, p. 229-241.

. A racionalidade dos formatos produtivos autogestionários. Sociedade e Estado. Brasília: UnB, v. 21, n. 2, p. 513-545, maio-ago. 2006.

GRANOVETTER, M. The Strength of Weak Ties. American Journal of Sociology. Chicago: University of Chicago Press, v. 78, n. 6 , p. 1360-1380, 1973.

. M. The Strength of Weak Ties: a Network Theory Revisited. Sociological Theory. Hoboken: Wiley-Blackwell, v. 1,p. 201-233, 1983.

HARVEY, D. Condição pós-moderna: uma pesquisa sobre as origens da mudança cultural. São Paulo: Loyola, 1996.

HOBSBAWM, E. Era dos extremos: o breve século XX 1914-1991. São Paulo: Companhia das Letras, 1995. 
LIN, N. Social Capital: a Theory of Social Structure and Action. Cambridge: Cambridge University Press, 2001.

MARTELETO, R.; SILVA, A. B. O. Redes e capital social: o enfoque da informação para o desenvolvimento local. Ciência da Informação, Brasília, DF, 33.3, 15/06/2005. Disponível em: $<$ http://www.ibict.br/cienciadainformacao/ viewarticle.php?id=563>. Acesso em: 09 jun. 2008.

PINTO, J. L. Economia solidária: de volta à arte da associação. Porto Alegre: Editora da UFRGS, 2006.

PORTES, A. Capital social: origens e aplicações na sociologia contemporânea. Sociologia: problemas e práticas. Lisboa: CIES, n. 33, p. 133-158, set. 2000a

. The Two Meanings of Social Capital. Sociological Fórum. Hoboken: Wiley-Blackwell, v. 15, n. 1, p. 1-12, 2000 b.

ROSENFIELD, C. A autogestão e a nova questão social: repensando a relação indivíduo-sociedade. Civitas. Porto Alegre: PUCRS, v. 3, n. 2, p. 395-415, jul.-dez. 2003.

SINGER, P. Introdução à economia solidária. São Paulo: Editora Fundação Perseu Abramo, 2002.

\section{Notas}

1 O presente artigo foi produzido como parte das atividades de pós-doutoramento, viabilizadas com suporte do CNPq e daUFRGS.

2 Na verdade, os autores utilizam as categorias de "capital social de ligação", "capital social de ponte" e "capital social de conexão". No entanto, na medida em que se busca estabelecer uma distinção mais precisa entre a configuração das relações sociais e os recursos por elas gerados (capital social), introduziu-se uma alteração na denominação das categorias originalmente formuladas.

3 Na medida em que o grupo pesquisado é relativamente pequeno e coeso, optou-se por uma abordagem qualitativa da ARS, sem o recurso aos procedimentos de quantificação e análise estatística das relações.

4 Foram realizadas 11 entrevistas com trabalhadoras da cooperativa entre os dias 31 de agosto e 12 de novembro de 2007, as quais autorizaram a utilização de seus depoimentos para fins acadêmicos.

5 Um exemplo da relação da Univens com entidades governamentais e não-governamentais como possibilidade de acessar mercados e serviços é o fato da cooperativa ser responsável pela produção de bolsas utilizadas pelos participantes do Fórum Social Mundial, realizado em Porto Alegre no ano de 2005.
6 Por motivos éticos damos nomes fictícios às trabalhadoras nas citações deste trabalho. Entretanto, a idade e a ocupação na cooperativa correspondem às informações reais coletadas em campo.

\section{Marcelo Kunrath Silva}

Pós-Doutor pela Brown University, Rhode Island, EUA

Mestre e doutor em Sociologia pela Universidade Federal do Rio Grande do Sul (UFRGS)

Professor do Departamento de Sociologia e do Programa de Pós-Graduação em Sociologia da UFRGS

\section{Gerson de Lima Oliveira}

Bacharel em Ciências Sociais pela UFRGS

\section{UFRGS}

Instituto de Filosofia e Ciências Humanas Departamento de Ciências Sociais.

Av. Bento Gonçalves, 9500 - Prédio A1 - Sala 109 Campus do Vale

Porto Alegre, RS - Brasil

CEP: 91509-900 